\title{
SHELF-LIFE STUDIES OF PLANTAIN STICKS ${ }^{1}$
}

Green plantains are becoming of increasing importance as a raw material for industrialization purposes in Puierto Rico. At present, they are being marketed frozen as partially cooked "tostones" and grated raw green plantains, as fried chips ${ }^{2}$ and as puree.

A new snack-type item prepared from green plantains, known as plantain sticks, ${ }^{3}$ was rated as very acceptable by a large taste panel. No information is available, however, on the shelf-life of this product.

This note presents results of shelf-life tests for plantain sticks packed in different media.

Plantains, as well as the tin cans and cellophane bags used in the tests, were obtained in the local market. Single and double cellophane bags of different yields ${ }^{4}$ coated with nitrocellulose and polyvinylidene chloride (PVC) were used.

Plantain sticks were prepared following the method developed by González et al. and packed in tin cans under vacuum and nitrogen and also in nitrocellulose, and PVC-coated cellophane bags. All the samples were stored under ambient conditions at temperatures ranging from $70^{\circ}$ to $90^{\circ} \mathrm{F}$. and a relative humidity between 60 and 95 percent.

Samples were analyzed at different time intervals for moisture, color, fat, and peroxide value. Moisture was determined by the vacuum oven method. ${ }^{5}$ Fat was measured as total ether extract using a Soxhlet type extractor. ${ }^{6}$ Peroxide value was determined by the Wheeler method $^{7}$ while color was measured with the Hunter Tristimulus Colorimeter using a yellow plate with $R d=59.4,9=+1.8, b=+52.4$ as a standard.

A trained taste panel evaluated the general quality of the plantain sticks periodically. A simplified method of the Kramer taste panel ${ }^{8}$ was followed

${ }^{1}$ Manuscript submitted to Editorial Board September 27, 1971.

2 Cancel, L. E., González, M. A., and Sánchez-Nieva, F., Elaboración de platanutre, Laboratorio de Tecnología de Alimentos, Est. Exp. Agr. Univ. P.R. Publ. Misc. 6, 1962.

- González, M. A., and Cancel, H. L., La Estación Experimental desarrolla un método para elaborar un nuevo producto "Snack" de plátano verde, Informe Téc. Núm. 24, September 27, 1967.

4 Yield = hundreds of sq. in./pound.

6 Official Methods of Analyses of the Association of Official Agricultural Chemists, 10th ed., 13.003, p. 191.

Ibid., 22.033, p. 331.

7 Wheeler, D. H., Oil and Soap 9, 89, 1932.

${ }^{8}$ Kramer, A., and Ditman, L. P., A simplified variable taste panel method for detecting flavor changes in vegetables treated with pesticides, Food Technol. 10 (3) : 155-9, 1956. 
to determine the general quality of the samples. Each sample was evaluated on a specific scale of 5 points, where +2 indicated very acceptable, +1 acceptable, 0 questionable, -1 slightly unacceptable; and -2 not acceptable.

There was an appreciable increase in the moisture content of the samples packed in cellophane bags (table 1). The results showed there was always a higher moisture absorption when samples were packed in nitrocellulose-

TAuLE 1.-Resulls of the chemical and sensory evaluation of plantain sticks packagel in differenl media

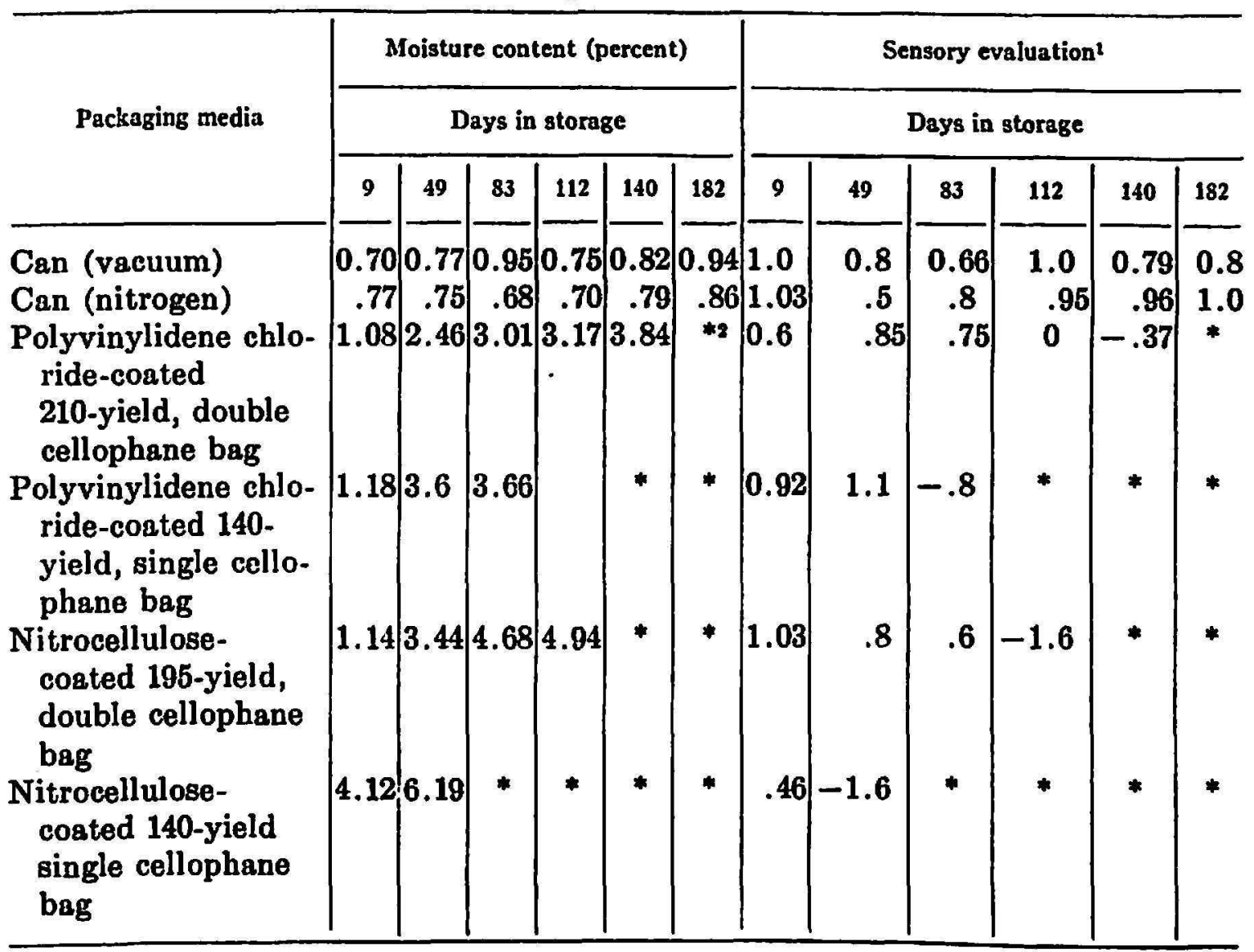

${ }^{1} \mathrm{~A}+2,-2$ scale of 5 points was used, where $+2=$ very acceptable, $+1=$ scceptable, $0=$ questionable, $-1=$ slightly unacceptable and $-2=$ not acceptable.

2 Asterisk indicates samples no longer acceptable.

coated cellophane than when packed in polyvinylidene chloride-coated cellophane, regardless whether the bags were single or double or of different yields. Double bags of higher yield of both offered better barrier against moisture pick-up.

The moisture content of the samples packed under vacuum and nitrogen remained fairly constant during the course of this study.

The data obtained on the sensory evaluation of the samples during storage are shown in table 1. The results indicate that the vacuum- and nitro- 
gen-packed samples were still acceptable after 6 months in storage while the quality of those packed in the different types of coated-cellophanes deteriorated.

Plantain sticks packed in PVC-coated 210-yield double cellophane bags were rejected at 140 days in storage, although they were rated as questionable at 112 days by the tasters. When the 140 -yield single bags were used plantain sticks were rejected at 83 days in storage.

Samples packed in nitrocellulose-coated 195-yield double cellophane bags were rejected at 112 days in storage; those packed in 140-yield single bags were rejected at 49 days.

The average fat content of the samples under study was 44.4 percent. There were slight differences in the peroxide value of the plantain sticks. These differences were not significant because the peroxide value did not reach the point of organoleptic rancidity of the 60 percentvegetable shortening to 40-percent lard blend used as frying medium. González et al. ${ }^{9}$ found that for detecting rancid flavors in similar products the peroxide value should be in the range of $40 \mathrm{meq} . / \mathrm{kg}$. of oil and the typical golden yellow color turns very light.

These results also indicate that for the packing of plantain sticks for the local market upon which the shelf-life for a product of this nature is not expected to be more than 60 days, sufficient shelf-life is obtained with PVC210-yield double cellophane bags. Acceptable results can also be obtained with nitrocellulose-coated 195-yield double cellophane bags.

PVC-coated 140-yield single cellophane and nitrocellulose-coated 140yield single cellophane bags are not recommended because of their inadequate protection to samples under storage.

Jose R. Cruz

Miguel A. Gonzailez

Food Technology Laboratory

- Gonzallez, M. A., Díaz-Negrón, E., and Sandoval, A. R., Studies on the stability of fried plantain chips, J. Agr. Univ. P.R. 53 (1): 67-74, 1969. 